\title{
Electrocardiographic Abnormality of Pure Posterior Myocardial Infarction
}

Key words: electrocardiogram, posterior myocardial infarction

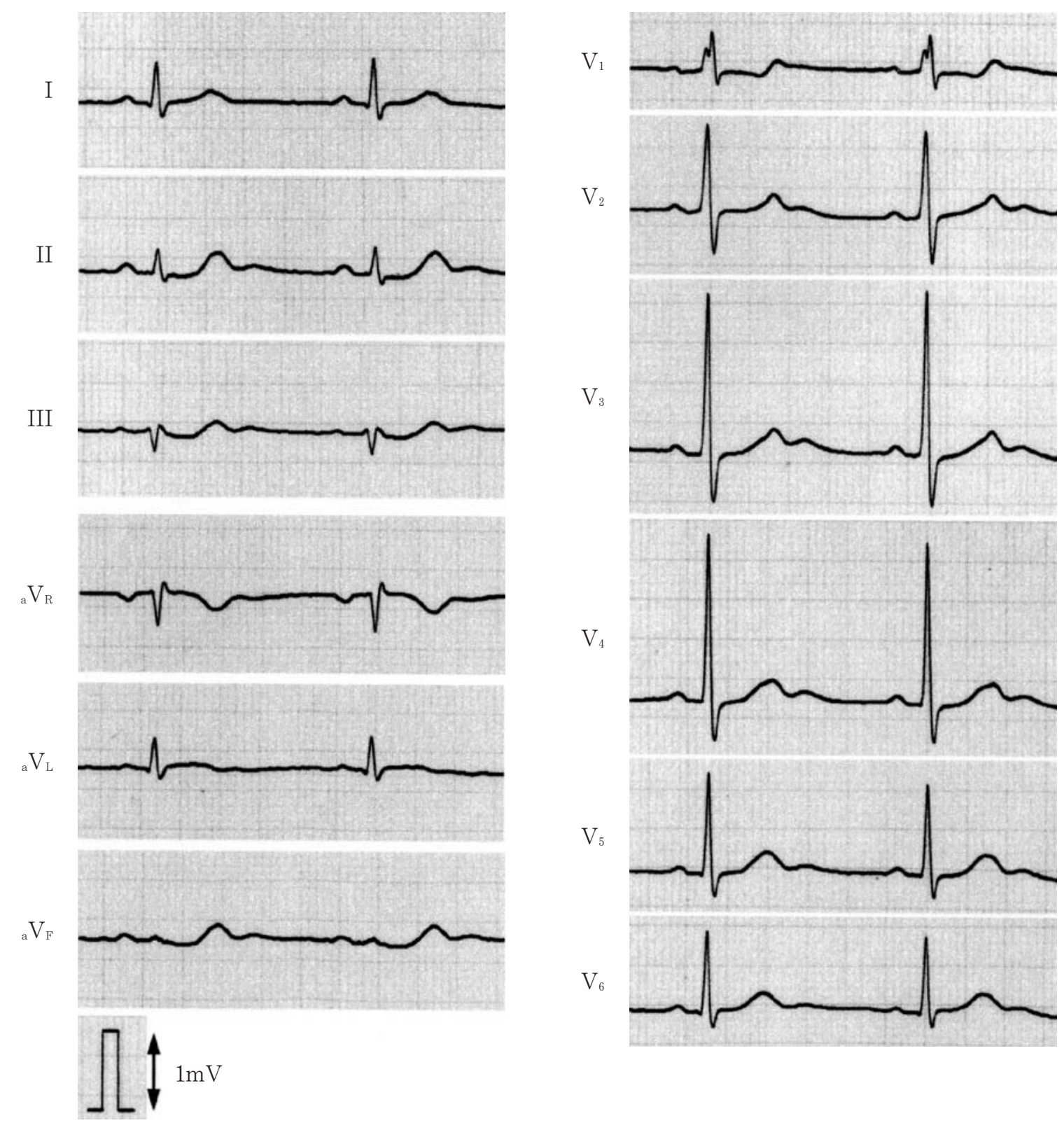

Figure 1. Electrocardiogram. Slight $S T$ elevation was present in lead $\mathbf{V}_{\mathrm{L}}$. Tall $\mathbf{R}$ waves with long duration were seen in leads $V_{1}$ and $V_{2}$. The $R$ amplitude was much lower in lead $V_{5}$ than in lead $V_{4}$. Marked positive $U$ waves were present in leads $V_{2}$ and $V_{3}$. 

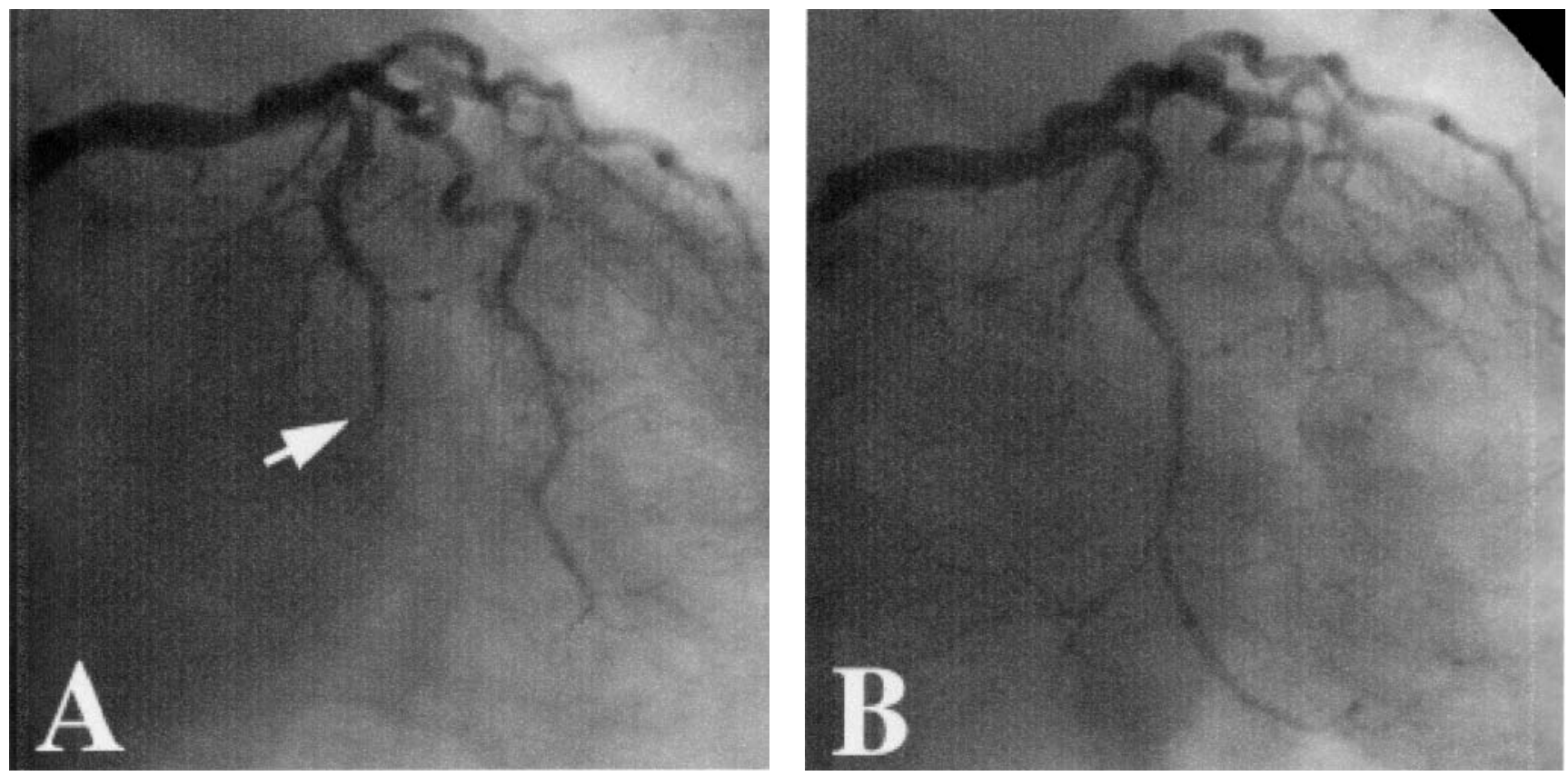

Figure 2. Coronary angiogram. (A) Left anterior oblique view of the left coronary artery showed occlusion of the posterior descending artery (arrow). (B) Perfusion of the posterior descending artery was improved after percutaneous transluminal coronary intervention.

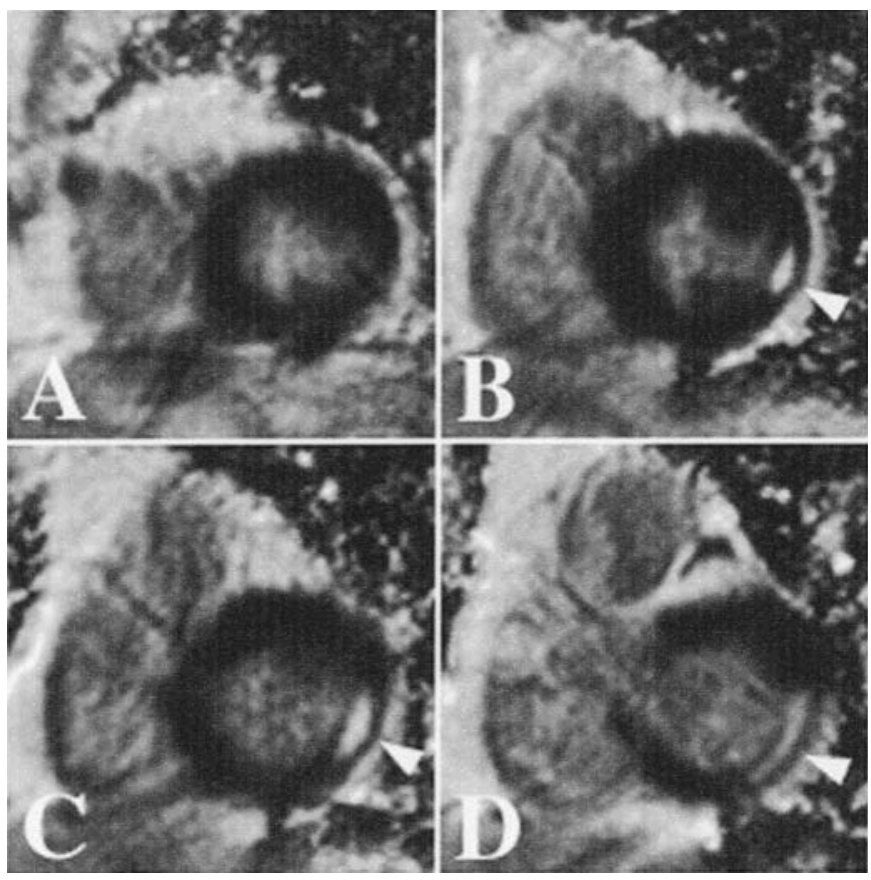

Figure 3. Gadolinium-enhanced T1-weighted magnetic resonance imaging from the mid-portion (A) to base (D) of the left ventricle in the short axis plane. The infarcted myocardium (arrowhead) of the posterior wall displayed high signal intensity. 
A 70-year-old woman was referred to Keiaido Hospital for chest discomfort, which had persisted for two days. A physical examination showed no remarkable abnormality. Electrocardiogram (ECG) revealed a slightly elevated ST segment in lead ${ }_{a} V_{L}$, initial $R$ waves of 80 msec with an R/S amplitude ratio $\geq 1$ in leads $V_{1}$ and $V_{2}$, and a much lower $R$ amplitude in lead $\mathrm{V}_{5}$ than in lead $\mathrm{V}_{4}$ (Fig. 1). In addition, marked positive $\mathrm{U}$ waves were seen in leads $\mathrm{V}_{2}$ and $\mathrm{V}_{3}$. Laboratory findings showed elevated cardiac enzymes (AST $181 \mathrm{U} / l$, LDH $471 \mathrm{U} / l$, CK 2,327 U/l). The patient was transferred to Gunma University Hospital due to differential diagnosis of pure posterior myocardial infarction (MI). A coronary angiogram demonstrated occlusion of the peripheral left circumflex artery (LCx) (Fig. 2A). A percutaneous transluminal coronary intervention was performed with satisfactory results (Fig. 2B). Cardiac magnetic resonance imaging revealed focal MI in the posterior wall (Fig. 3).

The patient was diagnosed with a pure posterior MI due to LCx occlusion. However, the ECG did not show abnormal records characteristic of MI, except for the slight ST elevation in lead ${ }_{\mathrm{a}} \mathrm{V}_{\mathrm{L}}$, suggesting a high lateral MI.

It is difficult to diagnose posterior MI by ECG without inferior or lateral MI. Abnormal R waves (duration $>40 \mathrm{msec}$ and/ or an $\mathrm{R} / \mathrm{S}$ amplitude ratio $\geq 1)$ in the right precordial leads $\left(\mathrm{V}_{1}\right.$ and/or $\left.\mathrm{V}_{2}\right)$ are thought to be markers for pure posterior MI (1). However, these symptoms also occur in right bundle branch block, Wolff-Parkinson-White syndrome, right ventricular hypertrophy and normal variants. Goldberger reported that a "drop off pattern" in the lateral precordial leads (a lower R amplitude in leads $\mathrm{V}_{5}$ and $\mathrm{V}_{6}$ than in leads $\mathrm{V}_{3}$ and $\mathrm{V}_{4}$ ) was a useful marker to distinguish posterior MI from normal variants (2). Subsequently, Kanemoto et al (3) proposed the following ECG criteria at the acute phase of posterior MI: 1) ST segment depression $\geq 0.1 \mathrm{mV}$ in two consecutive precordial leads, 2) prominent positive $\mathrm{U}$ waves $\geq 0.1 \mathrm{mV}$ in lead $\mathrm{V}_{2}$ or $\mathrm{V}_{3}$, and 3) $\mathrm{T} / \mathrm{U}$ ratio $\leq 4$ in leads $\mathrm{V}_{2}$ or $\mathrm{V}_{3}$. When two of the above criteria were positive, the diagnostic accuracy was $88.8 \%$ (3).

\section{References}

1) Perloff JK. The recognition of strictly posterior myocardial infarction by conventional scalar electrocardiography. Circulation 30: 706-718, 1964 .

2) Goldberger AL. Myocardial infarction: electrocardiographic differential diagnosis. 4th ed. Medical View Co., Ltd., Tokyo, 1993: 55-58 (Japanese edition).

3) Kanemoto N, Wang Y, Fukushi H, et al. Electrocardiographic characteristics of patients with left circumflex-related myocardial infarction in the acute phase without tented T waves or definite ST elevation. J Cardiol 26: 149-158, 1995 (in Japanese).

Yoichi Hoshino, Akira HaSEgawa*, Akihiko NAKAnO*, Michiko Endo*, Yoichi Motegi*, Kimihiko UMEZAwA*, Masahiko SUGUTA*, Takashi HATORI* and Masahiko KURABAYASHI*

The Division of Internal Medicine, Keiaido Hospital, Omama and *the Department of Medicine and Biological Science, Graduate School of Medicine, University of Gunma, Gunma

Received for publication February 9, 2004; Accepted for publication May 15, 2004

Reprint requests should be addressed to Dr. Yoichi Hoshino, the Division of Internal Medicine,

Keiaido Hospital, 504-6 Omama, Yamada-gun, Gunma 376-0101 